\title{
Endoscopic retrieval through a lumen-apposing metal stent of a biflanged metal stent that had been released into a peripancreatic fluid collection
}

We report a 60-year-old woman with a previous history of an endoscopically treated walled-off necrosis that developed 12 months after an 80-mm recurrent symptomatic pancreatic body pseudocyst. Drainage was attempted using a $16 \times 20-\mathrm{mm}$ biflanged metal stent (Nagi), but the stent was mistakenly released inside the collection. A rescue attempt was made to retrieve the stent and avoid surgical intervention.

At endoscopic ultrasound (EUS), the stent could be easily identified inside the pseudocyst, which appeared smaller than previously described, with limited fluid content ( $\mathbf{F i g} \mathbf{1} \mathbf{a}$ ). The collection was punctured with a $19 \mathrm{G}$ fine-needle aspiration needle and filled up with normal saline to create the space needed to place a larger caliber lumen-apposing metal stent (LAMS), a process that was difficult partly because of the limited distensibility of the collection. It was however possible to successfully position a $10 \times 20-\mathrm{mm}$ LAMS (Hot AXIOS) under complete EUS guidance ( $>$ Fig. $\mathbf{1}$ b) and its middle portion was dilated up to $20 \mathrm{~mm}$. A gastroscope was then introduced through the

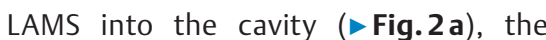
dislocated Nagi stent was trapped in a polypectomy retrieval net and was withdrawn from the cavity into the stomach under direct endoscopic view ( $\triangleright$ Video 1 ;

$>$ Fig. 2 b).

To the best of our knowledge, this report represents the first case of salvage of a biflanged metal stent that had been completely released inside a pancreatic collection during EUS-guided drainage. Unlike in the earlier report by Lakhtakia and colleagues [1], who described a case in which the proximal end of the stent was released in the cyst wall allowing subsequent endoscopic management with pneumatic tract dilation and repositioning of the stent with a rat-tooth forceps, in our patient, placement of a LAMS with a large diameter central por-
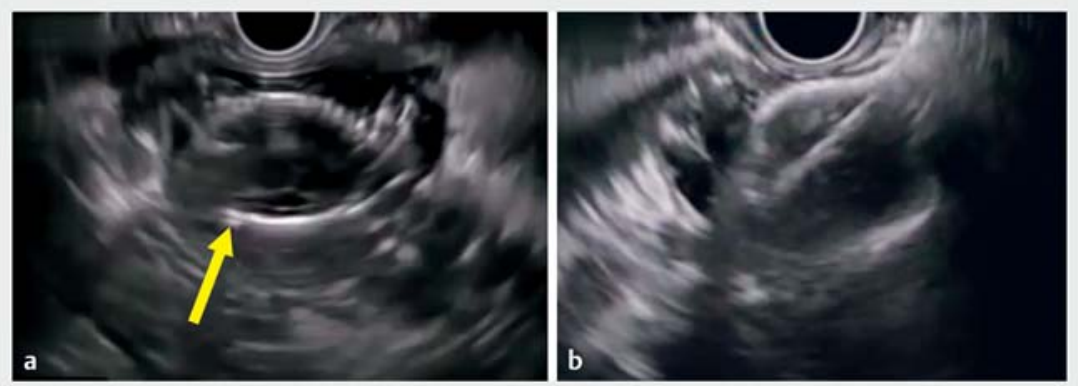

- Fig. 1 Endoscopic ultrasonography images showing:a the biflanged metal stent (yellow arrow) that had been released into the peripancreatic fluid collection; $\mathbf{b}$ opening of the distal flange of the lumen-apposing metal stent inside the peripancreatic fluid collection.
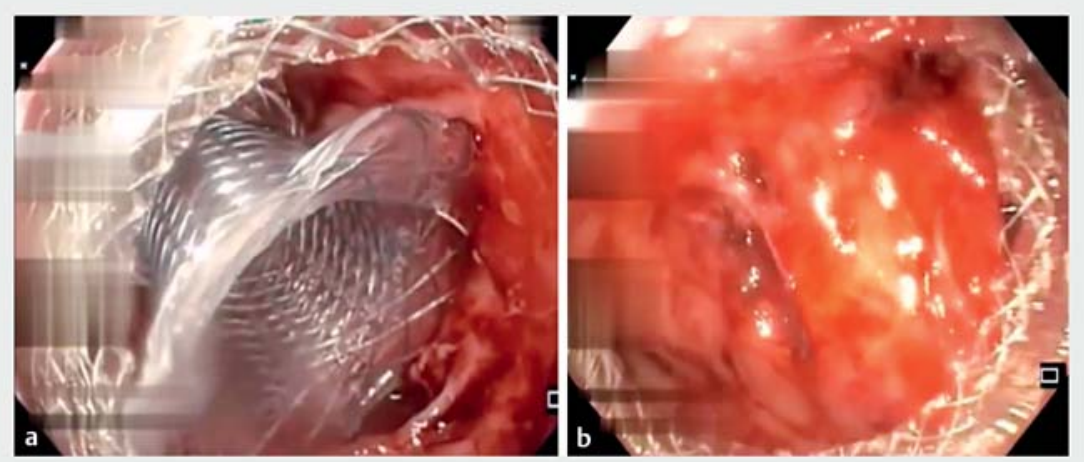

- Fig. 2 Endoscopic views showing: a the biflanged metal stent that had been released into the peripancreatic fluid collection; $\mathbf{b}$ the residual cavity seen through the indwelling lumenapposing metal stent after removal of the displaced biflanged metal stent.

tion was needed. This process could only be accomplished by refilling the collection with saline to create the proper space for stent placement and successfully avoided the need for a more invasive procedure.

Endoscopy_UCTN_Code_TTT_1AS_2AD

\section{Competing interests}

The authors declare that they have no conflict of interest.
The authors

Edoardo Troncone ${ }^{1}$, Giovanna Del Vecchio Blanco ${ }^{1}$, Carmelina Petruzziello ${ }^{1}$, Benedetto Neri ${ }^{1}$, Michelangela Mossa ${ }^{1}$, Giovanni Monteleone ${ }^{1}$, Alberto Larghi ${ }^{2}$

1 Department of Systems Medicine, University of Rome Tor Vergata, Rome, Italy

2 Digestive Endoscopy Unit, Fondazione Policlinico Universitario A. Gemelli, IRCCS, Rome, Italy 


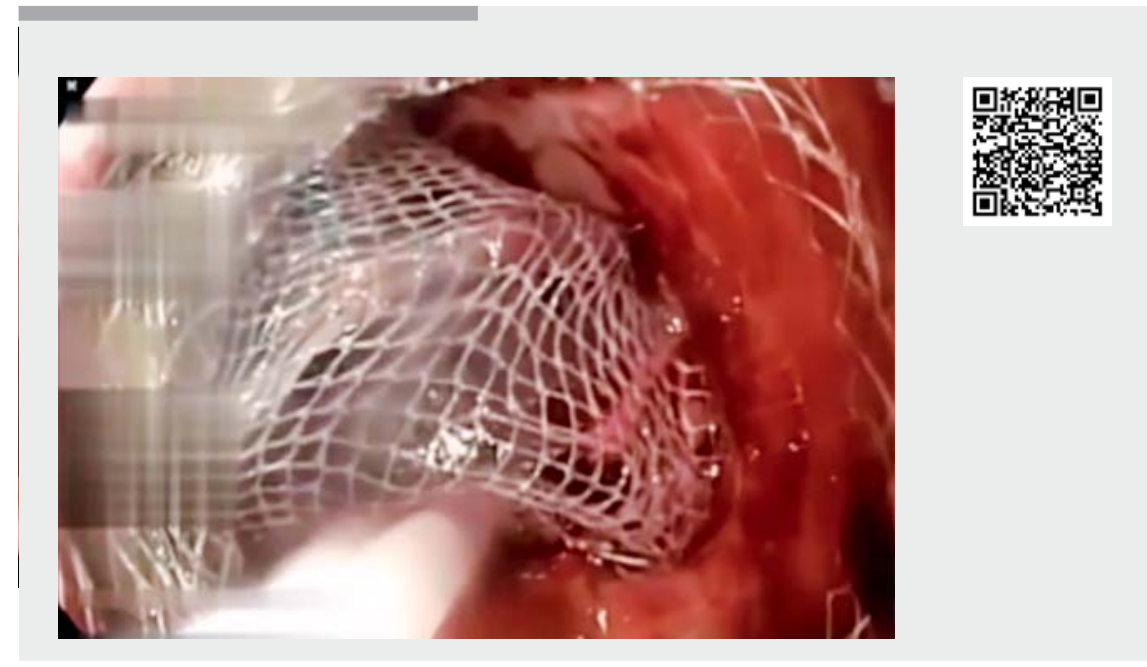

$\nabla$ Video 1 Endoscopic retrieval through a lumen-apposing metal stent of a biflanged metal stent that had been released into a peripancreatic fluid collection.

\section{Corresponding author}

\section{Edoardo Troncone, MD}

Department of Systems Medicine, University of Rome Tor Vergata, Via Montpellier 1, 00133 Rome, Italy

edoardo.troncone@ptvonline.it

\section{Reference}

[1] Lakhtakia S, Basha J, Nabi Z et al. Salvaging a malpositioned fully covered self-expanding metal stent for pancreatic fluid collection drainage. Endoscopy 2016; 48 (Suppl. 01): E180-E181

\section{Bibliography}

DOI https://doi.org/10.1055/a-1089-7606

Published online: 5.2 .2020

Endoscopy 2020; 52: E275-E276

(c) Georg Thieme Verlag KG

Stuttgart $\cdot$ New York

ISSN 0013-726X

\section{ENDOSCOPY E-VIDEOS}

https://eref.thieme.de/e-videos

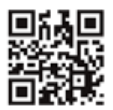

Endoscopy E-Videos is a free access online section, reporting on interesting cases and new techniques in gastroenterological endoscopy. All papers include a high quality video and all contributions are freely accessible online.

This section has its own submission website at

https://mc.manuscriptcentral.com/e-videos 